\title{
Self-care actions in patients with heart failure
}

\author{
Ações de autocuidado em portadores de insuficiência cardíaca
}

\author{
Heloisa Ribeiro do Nascimento ${ }^{1}$ \\ Vilanice Alves de Araújo Püschel ${ }^{1}$
}

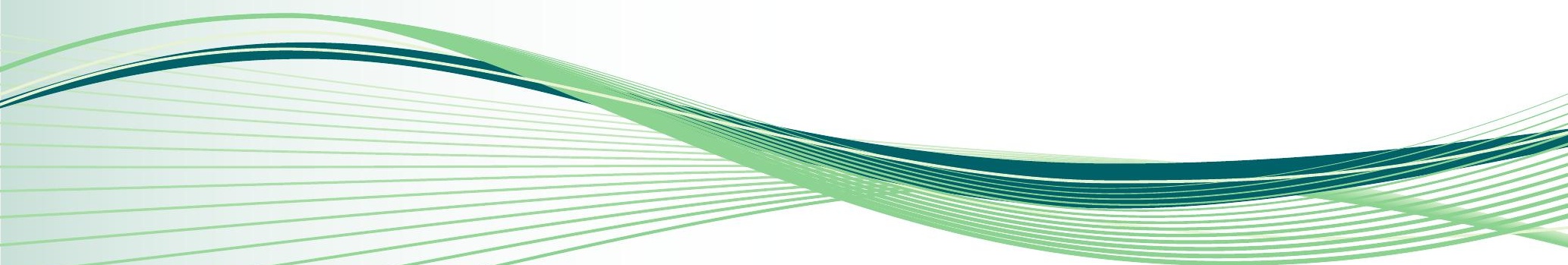

\section{Keywords}

Heart failure; Self-care; Patient education; Nursing care; Advanced practice nursing

Descritores

Insuficiência cardíaca; Autocuidado; Educação do paciente; Cuidados de enfermagem; Prática avançada de enfermagem

Submitted November 22, 2013

Accepted

December 4, 2013

\begin{abstract}
Objective: Identify self-care actions of patients with heart failure in two settings: the emergency and outpatient care units, and to identify the main precipitating factors of heart decompensation.

Methods: Cross-sectional study including 120 patients with heart failure in two settings, emergency and outpatient care units. Three validated instruments were used.

Results: There was no statistically significant difference between the self-care groups, with low scores on weight control, vaccination and communication. Most of the study population was elderly, retired, with Chagas disease, and patients from the emergency care unit had the worst levels of urea, creatinine and hemoglobin. Conclusion: The patients practice self-care when they perceive aggravation in their clinical conditions and communication, weight control and vaccination, with no difference between the groups. Heart failure in emergency room patients may be associated with sociodemographic factors and characteristics of severity, including hemodynamic profile related to prolonged hospitalization and high mortality.
\end{abstract}

\section{Resumo}

Objetivo: Identificar as ações de autocuidado em portadores de insuficiência cardíaca em dois cenários: no pronto socorro e no ambulatório e identificar os principais fatores precipitantes de descompensação.

Métodos: Estudo transversal no qual foram incluídos 120 portadores de insuficiência cardíaca em dois cenários: ambulatório e pronto socorro. Foram utilizados três instrumentos validados.

Resultados: Não houve diferença estatisticamente significativa do autocuidado entre os grupos, com baixa pontuação sobre o controle de peso, vacinação e comunicação. A maioria da população de estudo era de idosos, aposentados, com doença de Chagas e, no grupo do pronto socorro tivemos os piores níveis de ureia, creatinina e hemoglobina.

Conclusão: Os pacientes praticam o autocuidado na percepção de piora clínica e comunicação; controle de peso e vacinação, sem diferença entre os grupos. A descompensação nos pacientes do pronto socorro pode estar associada a fatores sociodemográficos e características de gravidade, incluindo o perfil hemodinâmico, relacionado à prolongada internação e alta letalidade.
Corresponding author

Heloisa Ribeiro do Nascimento Doutor Enéas de Carvalho Aguiar Avenue, 419, São Paulo, SP, Brazil. Zip Code: 05403-000 helorn@usp.br
${ }^{1}$ Escola de Enfermagem, Universidade de São Paulo, São Paulo, SP, Brazil.

Conflicts of interest: there are no conflicts of interest to declare. 


\section{Introduction}

Heart failure is the most increasing public health problem worldwide. ${ }^{(1)}$ In Brazil, it is one of the primary causes of hospitalization, being associated with high morbidity, mortality and health costs. ${ }^{(2)}$

Despite the efforts invested to control the problem, the evolution of patients is not changing, at least with regard to mortality and hospital readmissions for decompensated heart failure. ${ }^{(2)}$

One study on mortality following hospitalization showed that mortality rates one year after the first hospitalization are higher than in patients who were never hospitalized, remaining one of the most important risks for mortality. ${ }^{(3)}$

In this context, it is worth considering the importance of pharmacological and non-pharmacological measures, and educational activities in which nurses focus on teaching self-care and management of the disease. ${ }^{(4)}$ Non-pharmacological measures are important to reduce hospitalizations and improve the quality of life of patients with heart failure. ${ }^{(5)}$

The objective of this study is to identify the selfcare actions of patients with heart failure in two settings: the emergency and the outpatient care unit, and to identify the main precipitating factors of heart decompensation.

\section{Methods}

This was a cross-sectional study conducted in a large hospital in the city of São Paulo.

Data were collected during outpatient visits and in the emergency care unit, from patients with diagnosis of decompensated heart failure. Inclusion criteria were: age equal to or greater than 18 years, being able to understand and communicate, having been diagnosed with systolic heart failure, and undergoing treatment at the institution for at least twelve months. Exclusion criteria were: being on dialysis and awaiting a transplant, and/or participating in another research protocol.

The sample size calculation was performed using the total points of the adherence question- naire as the main variable of the study, using a standard deviation of 10.0 points, based on a previous study. ${ }^{(6)}$ Student's t-test was used as the statistical method for calculating N. Using a power of $90 \%, 5 \%$ significance and a detectable difference equal to 6.0 points between the groups for that variable, an $\mathrm{N}$ of 120 was found, divided into 60 patients in the outpatient care unit (group A), and 60 patients in the emergency care unit (group B).

Three research instruments were used: Instrument 1, which was specifically built for this study and had its content validated by two judges with recognized expertise in cardiology, and experience treating patients with heart failure, composed of three parts: 1. Socio-demographic profile: sex, marital status and cohabitants, religion, educational status, work status and income; 2. Knowledge of the disease, hospitalizations and actions due to the clinical aggravation of heart failure: time of knowledge regarding the disease, history of hospitalizations due to decompensated heart failure over the last twelve months, difficulty and location for weight control, as well as actions due to weight gain, dyspnea and edema, annual influenza vaccination, ${ }^{(7,8)}$ and topic on non-pharmacological treatment. ${ }^{(9)} 3$. Clinical profile, obtained from medical files: etiology, associated diseases, associated medications, functional class, echocardiography data, laboratory exams and implanted devices. Instrument 2, questionnaire on adherence to treatment, ${ }^{(6)}$ with 10 items (6 points each) addressing: correct use of medications, daily weight, fluid and salt restriction, alcohol consumption and attendance at appointments and exams, with possible scoring from 0 (poor adherence) to 60 (best adherence). Instrument 3, included after an initial analysis of the results and applied only to group B, composed of clinical and hemodynamic assessment with classification into four profiles: $\mathbf{1}$. Profile A: Patients without signs of congestion or with low output; 2. Profile B: Congested patients without low output 3. Profile C: Congested patients with low output; 4. Profile L: Patients without signs of congestion with low output; ${ }^{(10)}$ noninvasive monitoring; treatment and outcomes that included length of hospitalization, transfer, discharge and death. 
The results were presented in tables of absolute and relative frequencies of the categorical variables, with respective $\mathrm{P}$ values from Fisher's Exact test, to assess the existence of a significant association between these and groups A and B. For continuous variables, measurements of position, mean, standard deviation and confidence intervals for the mean and both groups were presented, as well as student's t-tests to compare the means between them. In cases in which the hypothesis of normality of the variable was rejected according to the Kolmogorov-Smirnov test, the nonparametric Mann-Whitney test was used. Using the variables that make up the proposed questionnaire for the study, analysis of internal consistency of the responses was done with Cronbach's alpha, as well as the importance of each question to assess adherence by the patients with heart failure. For the inferential analysis, a significance level of 5\% ( $a=0.05)$ was used, and all tests were completed under two-tailed hypothesis.
The development of the study complied with national and international ethical guidelines for studies involving human beings.

\section{Results}

There was a predominance of men and patients with a partner. Patients without a partner were more frequent in group B. The majority of patients claimed to have studied from one to eight years and $16(13 \%)$ reported being illiterate. Group B had a greater number of patients who were retired, unemployed, or who had stopped working. Comparison of the means showed significant differences in terms of age and income, with poorer results in group B (Table 1).

The data regarding the clinical profile showed that the most frequent diseases in group A were hypertension (83\%), dyslipidemia (43\%)

Table 1. Socio-demographic profile

\begin{tabular}{|c|c|c|c|c|c|}
\hline Variable & $\begin{array}{c}\text { Group A } \\
n(\%)\end{array}$ & $\begin{array}{c}\text { Group B } \\
n(\%)\end{array}$ & $\begin{array}{c}\text { All } \\
n(\%)\end{array}$ & $\mathrm{p}$-value & \\
\hline Age (years) & $55(8,8)$ & $59(13.9)$ & $57(11)$ & 0.048 & \pm \\
\hline Gender (male) & $41(68)$ & $37(62)$ & $78(65)$ & 0.566 & * \\
\hline Income (reais) & 1860(1056) & 1168(843) & 1520(1014) & $<0.001$ & \pm \\
\hline No individual income & $0(0)$ & $5(8.8)$ & $5(4.3)$ & 0.026 & * \\
\hline Marital status (partner) & $45(75)$ & $36(60)$ & $81(68)$ & 0.118 & * \\
\hline Living with husband/wife and children & $29(48.4)$ & $20(33.4)$ & $49(40.7)$ & 0.081 & * \\
\hline Living only with children & $9(15)$ & 20(33.3) & $29(24.2)$ & 0.081 & * \\
\hline Occupation (retired) & $27(45)$ & $38(63)$ & $65(54,2)$ & 0.002 & * \\
\hline Occupation (employed) & $24(40)$ & $6(10)$ & $30(25)$ & 0.002 & * \\
\hline Education (1 to 4 years) & $15(26.3)$ & $20(35.1)$ & $35(30.7)$ & 0.536 & * \\
\hline Education (5 to 8 years) & $22(38.6)$ & $16(28.1)$ & 38(33.3) & 0.536 & * \\
\hline Religion (Catholic) & $39(64.9)$ & $32(53.3)$ & $71(59.2)$ & 0.745 & * \\
\hline
\end{tabular}

Legend: Group A: outpatient care unit patients; Group B: emergency unit patients; values expressed as \pm mean and standard deviation based on Student's t-test; * number and percentage based on Fisher's exact test 
and obesity (22\%), and in group B they were hypertension (55\%), cardiac arrhythmia (38\%) and diabetes mellitus (30\%). The most frequent etiologies in both groups were ischemic (27\%) and hypertensive (27\%). The most frequent etiologies in group A were hypertensive (40\%) and ischemic (28\%), and in group B the most common were chagasic (30\%) and valvular (27\%). Regarding functional class, 52 patients (86\%) in group A were between classes I and II, and 57 (95\%) in group B were between classes III and IV. The drugs most commonly used consecutively were: beta-blockers, diuretics, angiotensin-converting enzyme II (ACE) inhibitors, spironolactone, aspirin, digitalis, anticoagulants, antiarrhythmics and vasodilators. There was a higher frequency of vasodilators in group B (40\%), and ACE inhibitors in group A (76\%). Descriptive statistics did not show a significant difference in the echocardiogram parameters, with ejection fraction of the left ventricle (EFLV) of 30\% (SD =9.9). Patients in group B had poorer results of urea, creatinine and hemoglobin.

The association between functional class and etiology showed that $27(100 \%)$ patients with chagasic etiology and $9(90 \%)$ patients with valvular etiology were in functional class III to IV, and 21 (63\%) patients with hypertensive etiology were in functional class I and II. Patients with ischemic etiology were in functional class I to IV.

The time of knowledge regarding the disease had a mean of nine years $(S D=8)$, and was not associated with the occurrence of previous hospitalizations. In group A, 40 (66\%) patients refused hospitalization, compared to 7 (12\%) in group B. Furthermore, of the 53 (88\%) patients in group B who reported having sought emergency care service or remained hospitalized, $16(27 \%)$ experienced four or more hospitalizations. The history of hospitalizations according to etiology also had significant difference: valvular $9(90 \%)$, chagasic $21(77.8 \%)$, ischemic 22 (66.7\%), hypertensive $16(48.5 \%)$ and idiopathic $3(75 \%)$. Regarding actions due to clinical aggravation and communication with the health care team, $105(88 \%)$ notified when they experienced breathlessness, 74 (63\%) notified when they had peripheral edema, and 70 (59\%) when they had recent weight gain. The others undertake: management of diuretic agents, reduction of liquids, waiting for spontaneous improvement, reduction of salt, rest and the use of herbal tea. Only 54 (45\%) patients had up-todate influenza vaccinations. Among the others, $31(50.8 \%)$ explained that they had not received instructions from the doctor or nurse. Regarding control of fluids, 97 (80\%) received instructions. Regarding weight control, only 33 (28\%) were provided with instructions, whereas 107 (89\%) reported it was easy to have their weight measured daily.

The internal consistency of the adherence questionnaire was assessed by Cronbach's alpha $(a=0.69)$. There was no statistically significant difference in total adherence score between the groups, with a mean of $46(\mathrm{SD}=8), 45.83( \pm \mathrm{SD}$ $=8.14)$ in group $\mathrm{A}$, and $46.35(\mathrm{SD}=7.97)$ in group $\mathrm{B}$. When analyzed separately, only items four and nine had statistically significant differences, with the best score in group B; and item two on daily weight had low scores in both groups (Table 2).

The fact that there is no significant difference in adherence to treatment and reporting aspects that demonstrate poorer profile in Group B led to the inclusion of specific data for this group.

Of the 60 patients, 44 (73\%) had signs of congestion. Among these, 22 (36\%) had signs of low cardiac output. Patients with low cardiac output (dry or wet) totaled 37 (61\%). The descriptive analysis of hospitalization time showed that the patients stayed $5.9(\mathrm{SD}=5.1)$ days in the emergency care unit, and were then transferred to other units where they remained in total, a mean of $19.6(S D=17.8)$ days. Two patients remained hospitalized on the day of data collection. Although $30 \%$ of the patients were discharged after being treated in the emergency care unit, mortality and hospitalization were very common (Table 3 ). 
Table 2. Self-care

\begin{tabular}{|c|c|c|c|c|}
\hline & Question & $\begin{array}{c}\text { Group A } \\
\text { mean(SD) } \\
(\mathrm{n}=60)^{*}\end{array}$ & $\begin{array}{c}\text { Group B } \\
\text { mean(DP) }\end{array}$ & p-value \\
\hline 1. & Do you regularly take your medicines according to the prescription? & $5.58(1.01)$ & $5.23(1.59)$ & 0.312 \\
\hline 2. & Have you weighed yourself on a daily basis? & $0.87(0.96)$ & $0.88(1.49)$ & 0.131 \\
\hline 3. & Do you limit adding salt to food? & $5.28(1.30)$ & $5.18(1.54)$ & 0.732 \\
\hline 4. & Do you add seasoning, sauces and other processed foods with salt to your meals? & $4.92(1.80)$ & $5.67(0.80)$ & 0.005 \\
\hline 5. & Have you eaten out without limiting salt? & $5.13(1.24)$ & $5.30(1.25)$ & 0.167 \\
\hline 6. & $\begin{array}{l}\text { Have you consumed soup, Jell- } 0 \text {, ice cream, juice, millk, tea, coffee, soda, etc. without } \\
\text { considering the quantity of liquid? }\end{array}$ & $4.15(2.31)$ & $4.00(2.38)$ & 0.708 \\
\hline 7. & Do you limit your ingestion of liquids according to instructions from your doctor or nurse? & $4.50(1.80)$ & $4.30(1.94)$ & 0.67 \\
\hline 8. & $\begin{array}{l}\text { Do you eat fruit high in liquids, such as orange, melon, watermelon, pineapple, coconut } \\
\text { juice, etc. without considering the amount of liquid? }\end{array}$ & $3.80(2.36)$ & $4.22(1.95)$ & 0.446 \\
\hline 9. & Do you consume alcoholic beverages? & $5.65(0.82)$ & $5.82(0.85)$ & 0.038 \\
\hline 10. & Have you missed any medical or nursing consultation, or scheduled exams? & $5.95(0.22)$ & $5.75(1.10)$ & 0.448 \\
\hline
\end{tabular}

Legend: Group A: outpatient care unit patients; Group B: emergency unit patients; SD: standard deviation

Table 3. Evaluation and treatment of decompensated heart failure

\begin{tabular}{lc}
\hline Evaluation and treatment & Group B(\%) \\
\hline Hemodynamic profile & \\
Perfile A - hot/dry & $1(1.6)$ \\
Profile B - hot/humid & $22(36.7)$ \\
Profile C - cold/humid & $22(36.7)$ \\
Profile L - cold/dry & $15(25)$ \\
Exams & \\
Electrocardiogram & $58(96.7)$ \\
Chest radiography & $51(85.0)$ \\
Treatment & \\
Diuretic (furosemide) & $31(51.7)$ \\
Inotropic (dobutamine) & $27(45.0)$ \\
Vasodilator & $8(13.3)$ \\
Volume replacement & $6(10.0)$ \\
Noninvasive ventilation & $3(5.0)$ \\
Evaluation by subspecialties team & $11(18.3)$ \\
Outcomes & \\
Transfer to primary nursing & $11(18.3)$ \\
Hospital discharge & $7(11.7)$ \\
Transfer to intensive care unit & $4(6.7)$ \\
\hline
\end{tabular}

Legend: Group $B=n=60$

\section{Discussion}

Limitations of this study include the fact that patients who participated in a previous study involving prolonged education, which may have influenced the score for adherence to treatment, were not identified. Furthermore, the assessment of self-care actions was self-reported, and may overestimate the results. Nevertheless, it is important to recognize the limitations of cross-sectional studies, besides the fact that descriptive correlational studies describe the relationship between variables, without establishing a causal relationship.

This study opens new perspectives for nursing care research, such as educational interventions for patients with advanced heart failure and/or specific to chagasic etiology, in addition to studies with palliative care programs in cases without possibility of heart transplant.

The data corroborate studies that affirm the importance of social support as an amenable need to be approached by the nurse, although results are still controversial. ${ }^{(11)}$ The low educational status observed may be associated with decompensated heart failure, because the authors affirm patients could not benefit from the educational directions and interventions. ${ }^{(12)}$ Regarding the differences of income, occupation, and age between the groups, 
other studies have highlighted the influence, mainly of low income, on the increase in hospital readmissions. ${ }^{(13)}$ The mean age was lower than that described in the international literature, as observed in another national study. ${ }^{(14)}$ Yet in our study, more elderly patients were observed in group B.

Despite ischemic etiology being the most frequent, the numbers are lower than those in international data. ${ }^{(15)}$ This difference may be related to the increased frequency of chagasic and hypertensive etiologies in the Brazilian context. Patients with heart failure from chagasic etiology showed poorer functional class results, followed by patients with valvular etiology, similar to one recent Brazilian study that recommends further studies for this specific group. ${ }^{(16)}$ The use of ACE inhibitors was less frequent in group B, although their use is indicated for patients with symptomatic or asymptomatic dysfunction of the left ventricle (LV), with class I recommendation and evidence level A. ${ }^{(9)}$ Factors such as anemia and impaired renal function are currently recognized as predictors of poor long-term prognosis in patients with severe heart failure. ${ }^{(17)}$

Data on the occurrence of unplanned hospitalizations in the last year are in line with the results of another study, in which the authors claim that hospitalization due to acute heart failure generates more hospitalizations, with rates of readmissions up to $50 \%$ within 12 months after discharge. (3) Most patients reported notifying the doctor or nurse about signs of decompensation, with breathlessness being most important, followed by edema and weight gain. Nevertheless, group B showed better management of diuretic agents. The rate of influenza and pneumococcal vaccination was low, similar to the results of another Brazilian study, ${ }^{(18)}$ suggesting the need for measures to increase the rate of vaccination against respiratory infections in patients with heart failure. Furthermore, although most patients reported ease of daily self-weighing, it was observed that orientation about weight control is poorly adopted by health care practitioners.

Compared to a previous study, ${ }^{(10)}$ the total score for treatment adherence remained within the mean values. The fact that no difference was found in the scores for adherence to treatment and self-care be- haviors, and there were differences in the sociodemographic and clinical profile between the groups, and in the characteristics of severity identified in patients from the group $B$, suggest that other factors predispose patients with heart failure to decompensation and hospital readmissions.

The hemodynamic profile with a predominance of congestion is the most common symptom of decompensated heart failure, according to national and international data. ${ }^{(14,19)}$ Our study frequently found the combination of congestion and low output, in addition to isolated low output. Therefore, the need for vasoactive drugs and mortality were very common, in addition to prolonged hospitalization. The severity and characteristics of the patients in group $B$ reinforce previous observations that patients with signs of cardiogenic shock, renal failure and Chagas disease with extensive myocardial damage, and those who are poorly oriented, have poorer progress in the group. ${ }^{(12,14,16)}$

Although negative results for adherence to treatment were not found, the length of hospitalization for compensation of heart failure patients in this study was higher than that reported in the literature, a mean of nine days for severely ill patients. (15) It is known that the length of hospitalization for compensation of patients is an important aspect, since it implies costs of treatment. The most severe patients with more comorbidities require more time for compensation and will bring more cost to the health system.

\section{Conclusion}

The results of this study show that patients practice self-care actions, with difficulties perceiving clinical deterioration related to recent weight gain and peripheral edema, communication with the health care team, weight control and influenza vaccination. Nevertheless, there was no significant difference between the self-care of patients in the outpatient and in the emergency care unit.

The main precipitating factors for decompensation are sociodemographic characteristics and se- 
verity factors, including hemodynamic profile with predominant pulmonary congestion, followed by low cardiac output related to prolonged hospitalization and high mortality in this group.

\section{Collaborations}

Nascimento HR and Püschel VAA have contributed to the study conception and project, analysis and interpretation of data, drafting the article, critical review of its relevant intellectual content, and final approval of the version to be published.

\section{References}

1. Lloyd-Jones D, Adams R, Carnethon M, Simone G, Ferguson B, Flegal Katherine, et al. Heart disease and stroke statistics--2009 update: a report from the American Heart Association Statistics Committee and Stroke Statistics Subcommittee. Circulation. 2009;119(3):e21-181.

2. Barretto AC, Del Carlo CH, Cardoso JN, Morgado PC, Munhoz RT, Eid MO, et al. Re-hospitalizações e morte por insuficiência cardíaca: índices ainda alarmantes. Arq Bras Cardiol. 2008;91(5):335-41.

3. Solomon SD, Dobson J, Pocock S, Skali H, McMurray JJ, Granger $\mathrm{CB}$, et al. Candesartan in heart failure: assessment of reduction in mortality and morbidity (CHARM) investigators. Influence of nonfatal hospitalization for heart failure on subsequent mortality in patients with chronic heart failure. Circulation. 2007;116(13):1482-7.

4. Püschel VA, Pinheiro CP. Cuidar do adulto e do idoso com doença cardiovascular: Abordagem psicossocial. Rev Paul Enf. 2006; 25:189-95

5. Rabelo ER, Aliti GB, Domingues FB, Ruschel KB, Brun A0. 0 que ensinar aos pacientes com insuficiência cardíaca e por quê: 0 papel dos enfermeiros em clínicas de insuficiência cardíaca. Rev Latinoam Enferm. 2007;15(1):165-70.

6. Bocchi EA, Cruz F, G Guimarães, Pinho Moreira LF, Issa VS, Ayub-Ferreira SM, et al. Long-Term prospective, randomized, controlled study using repetitive education at six-month intervals and monitoring for adherence in heart failure outpatients. The REMADHE Trial. Circ Heart Fail. 2009;1(2):115-124.

7. Jaarsma T, Strömberg A, Martensson J, Dracup K. Development and testing of the European Heart Failure Self-Care Behaviour Scale. Eur J Heart Fail. 2003;5(3):363-70.
8. Riegel B, Carlson B, Moser DK, Sebern M, Hicks FD, Roland V. Psychometric testing of the self care of heart failure index. J Card Fail. 2004;10(4):350-60.

9. Bocchi EA, Marcondes-Braga FG, Ayub-Ferreira SM, Rohde LE, Oliveira WA, Almeida DR, et al. Sociedade Brasileira de Cardiologia. III Diretriz Brasileira de Insuficiência Cardíaca Crônica. Arq Bras Cardiol. 2009; 93(1 Supl 1):1-71.

10. Montera MW, Almeida RA, Tinoco EM, Rocha RM, Moura LZ, RéaNeto A, et al. Sociedade Brasileira de Cardiologia. II Diretriz Brasileira de Insuficiência Cardíaca Aguda. Arq Bras Cardiol. 2009;93(3 Supl 3):1-65.

11. Dantas RA, Pelegrino VM, Garbin ML. Avaliação do apoio social e sua relação com variáveis sociodemográficas de pacientes com insuficiência cardíaca em seguimento ambulatorial. Cienc Cuid Saúde. 2007;6(4):456-62.

12. Smeulders ES, van Haastregt JC, Ambergen T, Stoffers $H E$, Janssen-Boyne JJ, Uszko-Lencer NH. Heart failure patients with a lower educational level and better cognitive status benefit most from a self-management group programme. Patient Educ Couns. 2010;81(2):214-21

13. Rathore SS, Masoudi FA, Wang Y, Curtis JP, Foody JM, Havranek $E P$, et al. Socioeconomic status, treatment and results with heart failure: findings from the national Heart Failure Project. Am Heart J. 2006;152(2):371-8

14. Mangini S, Silveira FS, Silva CP, Grativol PS, Seguro LF, Ferreira SM, et al. Insuficiência cardíaca descompensada na unidade de Emergência de Hospital Especializado em Cardiologia. Arq Bras Cardiol. 2008;90(6):400-6

15. Adams KF Jr, Fonarow GC, Emerman CH, Le Jemtel TH, Costango MR, Abraham WT, et al. Characteristics and outcomes of patients hospitalized for heart failure in the United States: rationale, design and preliminary observations from the first 100000 cases in the Acute Decompensated Heart Failure National Registry (ADHERE). Am Heart J. 2005;149(2):209-16.

16. Pelegrino VM, Dantas RA, Ciol MA, Clark AM, Rossi LA, Simões MV. Health-related quality of life in Brazilian outpatients with Chagas and non-Chagas cardiomyopathy. Heart Lung. 2011;40(3):e25-31.

17. Cardoso J, Brito Ml, Ochiai ME, Novaes M, Berganin F, Thicon T, et al. Anemia nos pacientes com insuficiência cardíaca avançada. Arq Bras Cardiol. 2010;95(4):524-29.

18. Martins WA, Ribeiro MD, Oliveira LB, Barros LS, Jorge AC, Santos $\mathrm{CM}$, et al. Vacinação contra influenza e pneumococo na insuficiência cardíaca - uma recomendação pouco aplicada. Arq Bras Cardiol. 2011;96(3):240-45

19. Thomas SS, Nohria A. Hemodynamic classifications of acute heart failure and their clinical application. Circ J. 2012;76(2):278-86. 